\title{
An invitation to contribute to Nature Clinical Practice Nephrology
}

\author{
Robert W Schrier and Suzanne J Farley
}

As an official publication of the International Society of Nephrology (ISN), all ISN full members receive Nature Clinical Practice Nephrology as a member benefit. The journal strives to meet the information needs of ISN members and other readers. Our aim is to be the first stop for practicing nephrologists and affiliated healthcare professionals in their ongoing effort to keep up to date with the latest advances in patient care.

To ensure that we cover the hottest, most clinically relevant new data and ideas, we have recruited an Advisory Board of eminent nephrologists (for a complete list see the front of the journal or go to the Nature Clinical Practice Nephrology website). Members of our Advisory Board practice in many different countries and subspecialties. This diversity ensures that the content of Nature Clinical Practice Nephrology is truly global in perspective and subject matter.

Advisory Board members suggest ideas for all article types-Research Highlights, Viewpoints, Practice Points, Reviews and Case Studies. The in-house editorial staff then discuss these ideas with the Editor-in-Chief, Robert Schrier, and select the most timely and clinically relevant to commission. Potential authors are then invited to write for us. Once received, all manuscripts are professionally edited so that they are concise, consistent and easy to digest.

We recognize the potential of ISN members and other readers to complement the expertise of our Advisory Board. As such, we invite you to submit article ideas by email to ncpneph@nature.com. What would you like
What would

you like to

read? Whose

opinion would

you like to

hear?...Just by

dropping us

a short email

you can help

to shape your

journal.

RW Schrier is Editorin-Chief, and SJ Farley is Editor, of Nature

Clinical Practice

Nephrology.

\section{Competing interests}

The authors declared

they have no competing

interests.

www.nature.com/clinicalpractice doi:10.1038/ncpneph0053 to read? Whose opinion would you like to hear? What recent advances do you think are going to most immediately affect the way you care for your patients? What are the best primary research papers that you have read in the past few weeks? Just by dropping us a short email you can help to shape your journal.

Would you like to contribute more directly to Nature Clinical Practice Nephrology? Our Case Study Advisor, Robert Reilly, also welcomes proposals for contributions to our Case Study section. Case Studies published in Nature Clinical Practice Nephrology are comprehensive teaching aids that provide full discussion of the reasoning behind management decisions, rather than simply being anecdotal reports. Any case with a unique aspect-whether it be an unusual presentation, a new diagnostic tool or a novel management strategy-is of interest. Send your suggestions (as a 200-word synopsis) to ncpneph@nature.com.

Peer review is an essential part of our editorial process. Managed by our in-house team, peer review ensures that commissioned content meets the highest standards of quality that are a hallmark of Nature Publishing Group. If you would like to be considered as a peer reviewer for Nature Clinical Practice Nephrology, please send full contact details plus your areas of expertise to ncpneph@nature.com. All peer reviewers receive a complimentary subscription to the journal in recognition of their valuable contribution.

Don't miss the opportunity to shape the content of Nature Clinical Practice Nephrology. Send us your ideas today! 